\title{
A mixed-methods sequential explanatory design comparison between COVID-19 infection control guidelines' applicability and their protective value as perceived by Israeli healthcare workers, and healthcare executives' response
}

\author{
Anat Gesser-Edelsburg ${ }^{1,2^{*}}$ (D) Ricky Cohen ${ }^{1}$, Nour Abed Elhadi Shahbari ${ }^{1}$ and Rana Hijazi ${ }^{1}$
}

\begin{abstract}
Background: Healthcare workers (HCWs) are on the front line of the COVID-19 outbreak, and their constant exposure to infected patients and contaminated surfaces puts them at risk of acquiring and transmitting the infection. Therefore, they must employ protective measures. In practice, HCWs in Israel were not fully prepared for this sudden COVID-19 outbreak. This research aimed to identify and compare: (1) Israeli HCWs' perceptions regarding the official COVID-19 guidelines' applicability and their protective value, and (2) HCWs executives' response to HWCs' concern regarding personal protective equipment (PPE) shortage.

Methods: A mixed-methods sequential explanatory design consists of: (1) An online survey of $242 \mathrm{HCWs}$ about the application of the guidelines and PPE, and (2) Personal interviews of 15 HCWs executives regarding PPE shortage and the measures they are taking to address it.

Results: A significant difference between the perceived applicability and protective value was found for most of the guidelines. Some of the guidelines were perceived as more applicable than protective (hand hygiene, signage at entrance, alcohol rub sanitizers at entrance, and mask for contact with symptomatic patients). Other were perceived as less applicable than protective (prohibited gathering of over 10 people, maintaining a distance of $2 \mathrm{~m}$ ', and remote services).
\end{abstract}

Conclusions: HCWs need the support of the healthcare authorities not only to provide missing equipment, but also to communicate the risk to them. Conveying the information with full transparency, while addressing the uncertainty element and engaging the HCWs in evaluating the guidelines, are critical for establishing trust.

Keywords: COVID-19, Infection control guidelines, Healthcare workers, Applicability and protective value, Perception

\footnotetext{
* Correspondence: ageser@univ.haifa.ac.il

${ }^{1}$ School of Public Health and the Health and Risk Communication Research

Center, University of Haifa, 199 Aba Khoushy Ave., Mount Carmel, 3498838 Haifa, Israel

${ }^{2}$ Head of Health Promotion Program, School of Public Health, Founding Director of the Health and Risk Communication Research Center, University of Haifa, 199 Aba Khoushy Ave., Mount Carmel, 3498838 Haifa, Israel
}

(c) The Author(s). 2020 Open Access This article is licensed under a Creative Commons Attribution 4.0 International License, which permits use, sharing, adaptation, distribution and reproduction in any medium or format, as long as you give appropriate credit to the original author(s) and the source, provide a link to the Creative Commons licence, and indicate if changes were made. The images or other third party material in this article are included in the article's Creative Commons licence, unless indicated otherwise in a credit line to the material. If material is not included in the article's Creative Commons licence and your intended use is not permitted by statutory regulation or exceeds the permitted use, you will need to obtain permission directly from the copyright holder. To view a copy of this licence, visit http://creativecommons.org/licenses/by/4.0/ The Creative Commons Public Domain Dedication waiver (http://creativecommons.org/publicdomain/zero/1.0/) applies to the data made available in this article, unless otherwise stated in a credit line to the data. 


\section{Background}

COVID-19 is a contagious viral infection, caused by newly identified virus [1]. Presentation can range from no symptoms to severe illness including pneumonia, respiratory failure, septic shock, and multi-organ failure, which may result in death [1].

There is a dispute as to how the virus is transmitted from one person to another (droplet or airborne transmission). Recently, the World Health Organization (WHO) declared that current information indicated that transmission is usually by droplets [2]. Droplet transmission occurs when a person is in close contact (within $1 \mathrm{~m}$ ) with someone who has respiratory symptoms (e.g., coughing or sneezing) and is therefore at risk of having his/her mucosae (mouth and nose) or conjunctiva (eyes) exposed to potentially infective respiratory droplets. However, the organization declares there is still uncertainty about airborne contagion, and concludes that "these initial findings need to be interpreted carefully" [2]. Therefore, some countries and organizations, including the US and European Centers for Disease Control and Prevention recommend airborne precautions for any situation involving the care of COVID-19 patients [3, 4].

On 30 January 2020, the WHO Director-General declared that the current outbreak constituted a public health emergency of international concern. Avoidance of exposure is the single most important measure for preventing COVID-19, so-called "social distancing." In the case of HCWs, they must wear PPE including gloves, medical masks, goggles or a face shield, and gowns, as well as for specific procedures, respirators and aprons [1, 3].

At the end of February 2020, the WHO published recommendations for the rational use of PPE in healthcare and community settings that aims to provide information about when PPE use is most appropriate [1, 5].

In Israel the Ministry of Health (MOH) at the beginning of March published "Guidelines for dealing with COVID-19 for health professionals in healthcare settings" [6] Even though Israel was one of the first countries to understand the severity of the epidemic, and the $\mathrm{MOH}$ had taken drastic measures to close the country's borders [7], the State Comptroller's report declared that Israel is not prepared for the COVID-19 epidemic and that the $\mathrm{MOH}$ has no organized plan to mitigate the shortage gaps in inpatient beds, medical teams, and PPE.

Considering the critical issues regarding guidelines for dealing with COVID-19 for healthcare professionals in healthcare settings and the lack of evaluation studies regarding the implications of the formal guidelines, this article seeks to: (1) Identify the attitudes and perceptions of Israeli HCWs regarding official guidelines (their applicability, protection of HCWs, and spread prevention); (2) Present behavioral practices proposed by the front-line HCWs; and (3) present senior health executives' response to the PPE shortage.

\section{Methods}

\section{Research design}

This research is based on mixed-methods sequential explanatory design [8]. The quantitative research is the main research, conducted through an online survey of 242 HCWs concerning the application of the guidelines and protective measures. The secondary qualitative research examined 15 healthcare executives' perceptions of the HCWs' reports of a PPE shortage, and the actions they took to address that issue using personal interviews [8].

\section{Sampling and data collection}

An online questionnaire was designed using the Qualtrics XM software for a deliberate nonprobability sampling [9] of the population of HCWs. This method was selected because the COVID-19 crisis requires social distancing, preventing face-to-face interviews. Furthermore, HCWs are the busiest population at this time.

The survey was distributed in March 2020 to HCWs using three main social media platforms: Facebook, WhatsApp, and Instagram. The first stage was deliberate intensive sampling through posts on specific social media forums for healthcare workers, such as the forum of nurses in Israel, the forum of Arab doctors in Israel, and more. Meanwhile, the questionnaire was sent to directors of health funds and hospitals and from there was distributed to their employees on WhatsApp. The second stage was snowball sampling [10] to reach broader circles of healthcare workers.

In the qualitative research, we performed intensive sampling of health executives and senior physicians. The study was advertised through WhatsApp groups, and executives and physicians who agreed to participate in the study contacted the researchers to schedule telephone interviews. Each interview lasted 20-30 min.

\section{Study population}

A total of $292 \mathrm{HCW}$ filled out the online questionnaire, however 50 (17\%) questionnaires were not fully completed. Those questionnaires were taken out of the sample, leaving $242 \mathrm{HCWs}$ (Table 1) who fully completed the questionnaire. That was done only after verifying that the main research findings did not differ when the whole set of questionnaires (292) was included in the statistical analysis.

In the qualitative research 15 health executives and senior physicians participated, including 6 (40\%) hospital directors, 3 (20\%) healthcare fund directors, 3 (20\%) directors of medical organizations, and 3 (20\%) senior physicians.

\section{The research process}

The quantitative questionnaire consisted of questions on sociodemographic details and questions on the guidelines 
Table 1 Healthcare workers socio-demographic characteristics $(N=242)$

\begin{tabular}{ll}
\hline Characteristic & $\mathrm{N}(\%)$ \\
\hline Sector & $34(14)$ \\
Physician & $109(45)$ \\
Nurse & $61(25)$ \\
Paramedic & $38(16)$ \\
Administration & \\
Location & $113(47)$ \\
Hospital & $129(53)$ \\
Community & \\
Gender & $71(29)$ \\
Male & $171(71)$ \\
Female & \\
Age & $69(29)$ \\
$<=30$ & $100(41)$ \\
$31-40$ & $37(15)$ \\
$41-50$ & $29(12)$ \\
$51-60$ & $7(3)$ \\
$61+$ &
\end{tabular}

for HCWs for the COVID-19 crisis based on MOH guidelines [6]. The questions about the $\mathrm{MOH}$ guidelines included questions about the applicability of each guideline and the protection it offers the worker and the public against contagion with the COVID-19 (See Additional file 1). For each guideline, the participants were asked to rank its level of applicability, and the way they perceive its protection against their own contagion and the public's. The ranking was based on a Likert scale from 1 (not at all) to 5 (very much). The next part of the questionnaire included open questions about the PPE and a question about other protective practices $\mathrm{HCW}$ serform, which are not in the official guidelines.

After finishing collecting the quantitative data, an interesting issue emerged from the open question in the qualitative research, about a shortage of PPEs on the ground. Therefore, in the personal interviews with hospital directors and senior officials, the two following questions were included: (1) How do you perceive the issue of PPE shortage? and (2) What actions are you taking to address this issue?

\section{Analysis}

In the first stage, we performed a statistical analysis to test the difference between the applicability of the guideline and its degree of protection/contagion prevention for each of the $\mathrm{MOH}$ guidelines. The comparisons between the applicability of the guidelines and the degree of protection and contagion prevention were made by a
Wilcoxon Signed-Ranks test for dependent measures. Furthermore, Friedman's test was conducted in order to check for efficacy differences among the guidelines.

In the second stage, the findings of the open questions in the questionnaire were coded into categories on the additional protective measures that do not exist in the guidelines. In the third stage the report of missing PPE was integrated with a content analysis of the personal interviews with the HCWs executives about their response to the PPE shortage.

\section{Reliability and validity}

Before the questionnaire was distributed, a pilot study was conducted among 20 participants in order to refine the questions and prevent information bias. The questions were written in Hebrew and translated into Arabic and later re-translated to Hebrew in order to check their wording. In addition, in order to test the validity of the guidelines we presented in the questionnaire, and in order to check for sectorial differences (physicians, nurses, paramedics and administrative workers) concerning perceptions of the protection guidelines, Kruskal-Wallis tests were performed on each guideline. Three perceptions were examined for each guideline; its level of applicability, its protectiveness for the healthcare worker, and its preventive level against the public's contagion. No significant differences were found between the 4 sectors on all these comparisons, which eliminates the need to consider this parameter in further analysis of these data (See Additional file 2).

The brief qualitative interviews with the directors were conducted in the Arabic and Hebrew languages. All of the interviews were recorded, transcribed, and translated into Hebrew. The transcription of the interviews in the Arabic language was performed by two Arabic-speaking researchers who speak both languages.

\section{Results}

The comparison between the applicability of each guideline and its protective value was done using a Wilcoxon Signed-Ranks test for dependent measures (Table 2).

A significant difference between applicability and protective value was found for several guidelines, except for three guidelines (using gloves and gown, mask for symptomatic patients, and questioning at entrance). Some of the guidelines are perceived as more applicable than protective (hand hygiene, signage at entrance, alcohol rub sanitizers at entrance, and mask for contact with symptomatic patients). Three guidelines are perceived as less applicable than protective (prohibited gathering over 10 people, maintaining a distance of $2 \mathrm{~m}$, and remote services).

Friedman's test was conducted in order to check for efficacy differences among the guidelines. The different 
Table 2 Guidelines applicability average degree compared to its protective value ("protecting me" and "prevent contagion") ( $N=242)$

\begin{tabular}{|c|c|c|c|c|c|}
\hline Guideline & Applicable & Protect/Prevent Contagion & Test Statistic $(\mathrm{S})^{a}$ & $\boldsymbol{p}$-value & Adjusted $p^{b}$ \\
\hline Hand hygiene & 4.5 & 4.0 & 4122.5 & $<.0001$ & $<.0001$ \\
\hline Gloves and gown & 3.9 & 3.7 & 960.0 & 0.02 & 0.20 \\
\hline Signage at entrance & 4.4 & 3.8 & 3190.5 & $<.0001$ & $<.0001$ \\
\hline Alcohol rub sanitizers at entrance & 4.3 & 4.0 & 1593.5 & $<.0001$ & $<.0001$ \\
\hline Mask for symptomatic patients & 3.8 & 3.9 & -446.0 & 0.20 & 0.89 \\
\hline Mask for contact with symptomatic patients & 4.3 & 3.9 & 1923.5 & $<.0001$ & $<.0001$ \\
\hline Prohibited gathering over 10 people & 3.6 & 3.8 & -1020.5 & 0.004 & 0.04 \\
\hline Maintaining a distance of $2 \mathrm{~m}^{\prime}$ & 3.0 & 3.7 & -3470.5 & $<.0001$ & $<.0001$ \\
\hline Questioning at entrance & 3.5 & 3.6 & -754.5 & 0.08 & 0.58 \\
\hline Remote services & 3.9 & 4.4 & -2277.0 & $<.0001$ & $<.0001$ \\
\hline
\end{tabular}

${ }^{a}$ Wilcoxon Signed-Ranks tests

b Sidak adjustment for multiple testing

guidelines were examined using an overall measure of efficacy which averages the applicability and the protective value of each guideline. Test results (Table 3) show significant differences $(\chi 2(9)=553.5, P<0.0001)$ between the guidelines.

Additional practices that do not appear in the official guidelines against COVID-19, were suggested by the HCWs (Table 4).

The HCWs also reported a shortage of PPEs. The main shortages reported (by rate of respondents) are of facemasks (19\%), gowns (16\%), general protective gear (10\%), disinfectant (10\%), gloves (7\%), and surgical masks (7\%).

The response of the HCWs executives to the HCWs' concern over PPE shortages included three main themes, that are present with their selected quotes.

(1) HCW' fears of contagion

"As deputy director I see a tremendous shortage of equipment. It is extremely difficult to deal with the situation because my staff members are afraid of contagion during treatment."

"Right now, I as a physician and the medical personnel around me are very exposed to the disease. They are barely protected, and it disturbs me. When a patient comes to my room, I don't know anything about them, what their condition is, whether they were exposed or not, infected or not. Our chances of contagion are very high. There is not sufficient protective gear, there are not even temperature checks."

"There is a feeling that protection of the human resource is insufficient, there is neither a health nor an economic safety net."

(2) Adjusting expectations and resource allocation

"There is tremendous anger among the staff about the equipment shortage. I try to solve it by setting

Table 3 A comparison of guideline applicability and protective value using an overall measure of efficacy $(\mathrm{N}=242)$

\begin{tabular}{|c|c|c|c|c|}
\hline Guideline & Overall measure of efficacy $^{a}$ & Chi-Square $^{\mathrm{b}}$ & DF & $p$-value \\
\hline Hand hygiene & 4.2 & 317.52 & 9 & $<0.001$ \\
\hline Remote services & 4.2 & & & \\
\hline Alcohol rub sanitizers at entrance & 4.2 & & & \\
\hline Signage at entrance & 4.1 & & & \\
\hline Mask for contact with symptomatic patients & 4.1 & & & \\
\hline Mask for symptomatic patients & 3.8 & & & \\
\hline Gloves and gown & 3.8 & & & \\
\hline Prohibited gathering over 10 people & 3.7 & & & \\
\hline questioning at entrance & 3.5 & & & \\
\hline Maintaining a distance of $2 \mathrm{~m}$ & 3.3 & & & \\
\hline
\end{tabular}

averages the applicability and the protective value of each guideline

${ }^{\mathrm{b}}$ Friedman's test 
Table 4 Additional practices suggested by the HCWs that do not appear in the official guidelines against COVID-19

\begin{tabular}{|c|c|}
\hline Practice No. & Practice description \\
\hline 1 & $\begin{array}{l}\text { Eating healthy, vitamin C-fortified food, and drinking a lot } \\
\text { of water }\end{array}$ \\
\hline 2 & Rinsing nostrils with water and soap after shift \\
\hline 3 & Disinfecting personal belongings before going home \\
\hline 4 & $\begin{array}{l}\text { Disinfecting cell phone, keyboard, mouse, and other } \\
\text { equipment throughout the day }\end{array}$ \\
\hline 5 & $\begin{array}{l}\text { Changing clothes and disinfecting shoes when entering } \\
\text { the house }\end{array}$ \\
\hline 6 & Washing work clothes separately \\
\hline 7 & Opening doors with elbow \\
\hline 8 & Thorough cleaning of surfaces and chairs \\
\hline 9 & Cleaning steering wheel and car door handles \\
\hline 10 & Showering at the end of shift before going home \\
\hline
\end{tabular}

an optimal protection level for use per team. The idea is to control the amounts and not let the workers go crazy..."

"I sat with all the teams, from all the departments in the clinic, we developed a work procedure, which team members need to be protected, and then together we came up with a "portion" of PPE based on the number of staff members, the number of patients, and which needs or cases they deal with. Every morning each team gets its portion. It will prevent misunderstandings and help the team understand the situation better."

(3) Remote services.

"We use videoconferencing in the treatment room, to reduce to a minimum the medical staff's exposure to patients and contagion."

"Currently the communication between the medical staff and the COVID-19 patients in the departments is remote, the communication is by intercom. The medical staff is not exposed to the confirmed patients."

\section{Discussion}

HCWs are on the front line of the COVID-19 outbreak, and their constant exposure to infected patients and contaminated surfaces puts them at risk for acquiring and transmitting the infection. Current global stockpiles of PPE are insufficient, driven not only by the number of COVID-19 cases but also by misinformation, panic buying and stockpiling $[1,11,12]$. Major distributors in the United States have already reported shortages of PPE $[3,13]$.

The findings of the present study point to the gap the HCWs perceive between the applicability of the existing guidelines and the protection of HCWs against contagion and infecting the public. These findings indicate the gap that has been documented in the literature, not only in the COVID-19 epidemic, between the official infection prevention guidelines and what happens on the ground [14].

The findings of the present study indicate that three guidelines are perceived as less applicable than protective: prohibited gathering of over 10 people, maintaining a distance of $2 \mathrm{~m}$ ', and remote services.

A possible interpretation to that is that the Israeli healthcare system has fewer staff positions and manpower than the Organisation for Economic Co-operation and Development (OECD) countries [15]. Israel has a tremendous overload on its healthcare system that is reflected by long lines [15-17]. The HCWs feel they cannot question the people who come in during the coronavirus crisis because they do not have enough time and there is a personnel shortage. In addition, since the hospitals and health funds are at full capacity all the time, during the COVID-19 crisis the pressure increases, and it is difficult to reduce the congregating and maintain a distance between people. Another possible explanation for the difficulty to maintain a distance is the cultural component. Israeli society has a culture of social intimacy where it is not common to keep a physical distance. Moreover, there are geographical areas in Israel with high population density where people congregate, such as the Arab and ultra-Orthodox communities. In the COVID-19 crisis in Israel certain populations have reportedly had difficulty following the guidelines, making it hard for the HCWs to maintain the specific guidelines concerning social distancing. For example, the ultraOrthodox community in Israel found it difficult to follow the guidelines and suffered from some of the highest infection rates in the country $[18,19]$.

The findings also indicated that some guidelines were perceived as more applicable than protective, such as hand hygiene, and alcohol rub sanitizers at entrance. Hand hygiene $(\mathrm{HH})$ is the single most effective way to reduce the spread of germs that cause respiratory disease [20]. HH after removing PPE is particularly important to remove any pathogens that might have been transferred to bare hands during the removal process [3].

One explanation for the findings of the present study that $\mathrm{HCW}$ s view $\mathrm{HH}$ as less protective of them might be the cognitive bias that exists among many of them, as it does in the general public, whereby they perceive PPE as a solution but forget to perform $\mathrm{HH}$ in the course of their work [21].

This interpretation is consistent with other research in the literature about the prevention of hospital-acquired infections, which indicates that despite a variety of interventions conducted for HCWs, the levels of compliance 
with $\mathrm{HH}$ still remain low at $50-60 \%$ [22-24]. during the COVID-19 crisis Reports from China indicate that suboptimal $\mathrm{HH}$ after contact with patients was linked to COVID-19 [25, 26]. Long exposure time to large numbers of infected patients directly increased the risk of HCW infections [11, 12].

Another guideline perceived as applicable but less protective is masks for contact with symptomatic patients. The professional literature indicates uncertainty about the effectiveness of wearing masks. Some say that wearing a mask can lead to false confidence [27]. It is possible that the dispute about the degree of protection from masks led the respondents to indicate a gap between applicability and protection. It is also possible that the uncertainty that still exists about the transmission of the coronavirus (droplet or airborne) also contributed to the gap found in regard to masks between its applicability and the degree of its protection against contagion [2].

Recent studies in the field of infection control indicate that the official guidelines focus on the temporal order of actions in their broadest sense and cannot be totally comprehensive as exigency situations arise from the dynamic nature of the work, that exist in the care continuum [28, 29].

Respectively, in a crisis such as the COVID-19 epidemic, the staff faces new situations they did not conceive of before, as the virus spreads. Therefore, in the study we asked the respondents to share with us additional practices they perform that cannot be found in existing guidelines. The HCWs raised creative practices that indicate the importance of including the staff when confronting an epidemic crisis. Guidelines that are handed down from above are insufficient in a changing reality and it is important to hear the staff and accommodate them.

This study indicates there is a PPE shortage of for HCWs in Israel like in other countries [30]. Many of the HCWs (69\%) noted the PPE shortage. The HCWs executives interviewed for this research noted that the PPE shortage led to feelings of anger and frustration among the HCWs. During the crisis in Israel due to the PPE shortage for its employees, the $\mathrm{MOH}$ issued a statement at a press conference in mid-March, saying that HCWs do not need to wear PPE regularly but rather consider the situations in which they should do so [31].

Following the $\mathrm{MOH}$ statement, senior doctors from across the country came together and sent a letter to the government stating that their voices were not being heard, and that the state was abandoning them due to the severe shortage of PPE [32, 33]. The MOH statement was perceived as an excuse to cover up the inadequacy of the Israeli healthcare system, of which the PPE shortage is only one example [7].

\section{Limitations}

The research limitation is that this is not a representative sample of all HCWs in Israel. However, the questionnaire was filled out by diverse sectors of the Jewish and Arab populations working in the Israeli healthcare system, both in the community and in hospitals. Follow-up studies might examine HCWs' perceptions concerning the guidelines for treating COVID-19 patients: guidelines about care, their level of applicability, and suggestions from the staff can contribute important information to the healthcare system.

\section{Conclusions}

The HCWs on the front line of this global crisis need the support of the authorities not only to provide missing equipment, but also to communicate the risks to them. Emerging infection diseases communication [34] is a critical strategy not only for conveying information to the general public, but also for HCWs [35-37]. Furthermore, including the personnel, while discussing with them the level of applicability of the guidelines and the way they perceive the risks, can help the authorities communicate with their staff effectively and adjust the guidelines to the reality on the ground. Furthermore, including the HCWs and enabling them to contribute additional solutions that can prevent infection is significant and can help the overall effort.

\section{Supplementary information}

Supplementary information accompanies this paper at https://doi.org/10. 1186/s13756-020-00812-8.

Additional file 1: Table S5. Questionnaire for healthcare workers.

Additional file 2: Table S6. Guideline applicability and protective value: a comparison between sectors (Kruskal-Wallis Tests) $(N=242)$.

\section{Abbreviations}

HCWs: Healthcare workers; $\mathrm{HH}$ : Hand hygiene; $\mathrm{MOH}$ : Ministry of Health; PPE: Personal protective equipment; WHO: World Health Organization

\section{Acknowledgements}

The authors would like to thank all the participants of this study.

\section{Authors' contributions}

AGE is the principal investigator and she has conceptualized the study, data analysis written the manuscript and taken full responsibility for the study. RC, NAES and $\mathrm{RH}$ are co-researchers who participated in the conceptualized of the study, data analysis and written the manuscript. The author(s) read and approved the final manuscript

\section{Funding}

None.

Availability of data and materials

Requests for more detailed information regarding the study can be addressed to the corresponding author.

Ethics approval and consent to participate

This study was approved by the ethics committee of The Faculty of Social Welfare and Health Sciences at the University of Haifa (confirmation number 
08/22). All the study participants gave their consent to participate in the research. The research does not provide any medical or personal information by which each participant can personally identified, thus anonymity it being ensured.

\section{Consent for publication}

All the study participants gave their consent to publish the research.

\section{Competing interests}

The authors declare that they have no competing interests.

\section{Received: 10 April 2020 Accepted: 28 August 2020}

Published online: 04 September 2020

\section{References}

1. World Health Organization. Rational use of personal protective equipment for coronavirus disease (COVID-19): interim guidance, 27 February 2020. Geneva: World Health Organization; 2020. Contract No: WHO/2019-nCov/ IPCPPE_use/2020.1.

2. World Health Organization. Modes of transmission of virus causing COVID19:implications for IPC precaution recommendations. Scientific Brief. 29 March 2020. Geneva: World Health Organization; 2020. Contract No.: WHO/ 2019-nCoV/Sci_Brief/Transmission_modes/2020.2

3. Centers for Disease Control and Prevention. Interim Infection Prevention and Control Recommendations for Patients with Suspected or Confirmed Coronavirus Disease 2019 (COVID-19) in Healthcare Settings. Atlanta, GA: Centers for Disease Control and Prevention; 2020.

4. European Centre for Disease Prevention and Control. Infection prevention and control for COVID-19 in healthcare settings - Third update. 31 March 2020. Stockholm: ECDC; 2020

5. World Health Organization. Responding to community spread of COVID-19: interim guidance, 7 March 2020. Geneva: World Health Organization; 2020 Contract No.: WHO/COVID-19/Community_Transmission/2020.1.

6. Sadetsky S, Ezra V. Guidelines for dealing morbidity from the new COVID-19 - 1.4.2020 update - update 13. Jerusalem: Ministry of Health Israel; 2020.

7. The State Comptroller. The hospitalization distress. Jerusalem: The State Comptroller and Ombudsman of Israel; 2020.

8. Creswell JW. Qualitative inquiry and research design: choosing among five approaches. Thousand Oaks, CA: Sage; 2013.

9. Vehovar V, Toepoel V, Steinmetz S. Non-probability sampling. In: Wolf C, Joye D, Smith TW, Fu YC, editors. The SAGE handbook of survey methodology. London: Sage Publications; 2016. p. 329-45.

10. Ulin PR, Robinson ET, Tolley EE. Qualitative methods in public health: a filed guide for applied research. San Francisco, CA: Jossey-Bass; 2005

11. McMichael TM, Currie DW, Clark S, Pogosjans S, Kay M, Schwartz NG, et al. Epidemiology of Covid-19 in a long-term Care Facility in King County, Washington. N Engl J Med. 2020. https://doi.org/10.1056/NEJMoa2005412.

12. Zhou P, Huang Z, Xiao Y, Huang X, Fan XG. Protecting Chinese Healthcare Workers While Combating the 2019 Novel Coronavirus. Infect Control Hosp Epidemiol. 2020:1-4. https://doi.org/10.1017/ice.2020.60.

13. Ranney ML, Griffeth V, Jha AK. Critical supply shortages - the need for ventilators and personal protective equipment during the Covid-19 pandemic. N Engl J Med. 2020. https://doi.org/10.1056/NEJMp2006141.

14. Srigley JA, Corace K, Hargadon DP, Yu D, MacDonald T, Fabrigar L, et al. Applying psychological frameworks of behaviour change to improve healthcare worker hand hygiene: a systematic review. J Hosp Infect. 2015; 91(3):202-10. https://doi.org/10.1016/j.jhin.2015.06.019.

15. OECD. OECD data Israel. 2020.

16. Chernichovsky D, Kfir R. The general hospitalization system in Israel: update. Policy paper 03.2019. Israel: Taub Center for Social Policy Studies. Israel: Taub Center for Social Policy Studies; 2019.

17. Knesset. Protocol 7 From the Finance Committee meeting 4.11.2019. Jerusalem; 2019

18. Agassi Y. Awareness and leadership failure: the attempt to curb the Corona in ultra-Orthodox society. 04.04.2020. Kan: Walla News; 2020.

19. Haaertz. Corona in Israel - all data. 3.4.2020. Haaertz: Walla News; 2020

20. Allegranzi B, Gayet-Ageron A, Damani N, Bengaly L, McLaws ML, Moro ML, et al. Global implementation of WHO's multimodal strategy for improvement of hand hygiene: a quasi-experimental study. Lancet Infect Dis. 2013;13(10):843-51. https://doi.org/10.1016/S1473-3099(13)70163-4.
21. Sani Y. Stop wearing gloves. They don't really protect you. 27.03.2020: Walla News; 2020

22. Boyce JM, Pittet $D$. Healthcare infection control practices advisory $C$, force HSAIHHT. Guideline for hand hygiene in health-care settings. Recommendations of the healthcare infection control practices advisory committee and the HIPAC/SHEA/APIC/IDSA hand hygiene task force. Am J Infect Control. 2002;30(8):S1-46. https://doi.org/10.1067/mic.2002.130391.

23. Erasmus V, Daha TJ, Brug H, Richardus JH, Behrendt MD, Vos MC, et al. Systematic review of studies on compliance with hand hygiene guidelines in hospital care. Infect Control Hosp Epidemiol. 2010;31(3):283-94. https:// doi.org/10.1086/650451.

24. Whitby M, Pessoa-Silva CL, McLaws ML, Allegranzi B, Sax H, Larson E, et al. Behavioural considerations for hand hygiene practices: the basic building blocks. J Hosp Infect. 2007;65(1):1-8. https://doi.org/10.1016/j. jhin.2006.09.026.

25. Ran L, Chen X, Wang Y, Wu W, Zhang L, Tan X. Risk factors of healthcare workers with Corona virus disease 2019: a retrospective cohort study in a designated Hospital of Wuhan in China. Clin Infect Dis. 2020. https://doi. org/10.1093/cid/ciaa287.

26. Yang Y, Wang H, Chen K, Zhou J, Deng S, Wang Y. Shelter hospital mode: how to prevent novel coronavirus infection 2019 (COVID-19) hospitalacquired infection? Infect Control Hosp Epidemiol. 2020:1-4. https://doi.org/ 10.1017/ice.2020.97

27. Maclntyre $C R$, Chughtai AA. Facemasks for the prevention of infection in healthcare and community settings. BMJ. 2015;350:h694. https://doi.org/10. 1136/bmj.h694.

28. Cohen R, Gesser-Edelsburg A, Singhal A, Benenson S, Moses AE. Deconstruction of central line insertion quidelines based on the positive deviance approach-reducing gaps between guidelines and implementation: a qualitative ethnographic research. PLoS One. 2019;14(9):e0222608. https:// doi.org/10.1371/journal.pone.0222608

29. Gesser-Edelsburg A, Cohen R, Halavi AM, Zemach M, van Heerden PV, Sviri $\mathrm{S}$, et al. Beyond the hospital infection control guidelines: a qualitative study using positive deviance to characterize gray areas and to achieve efficacy and clarity in the prevention of healthcare-associated infections. Antimicrob Resist Infect Control. 2018;7:124. https://doi.org/10.1186/s13756-018-0418-x.

30. Belingheri M, Paladino ME, Riva MA. Beyond the assistance: additional exposure situations to COVID-19 for healthcare workers. J Hosp Infect. 2020. https://doi.org/10.1016/j.jhin.2020.03.033.

31. Gal I. Ministry of Health guidance to physicians and pharmacist: No routine PPE is necessary. 21.3.2020. YNET: Walla News; 2020.

32. Hilaie $\mathrm{S}$. Dozens of department and clinic managers are demanding to replace the director general of the Ministry of Health. 23.3.2020. YNET: Walla News; 2020.

33. Hilaie S, Lukash A. More than 20 healthcare crew members were infected by Corona: "Insufficient basic PPE", 16.3.2020. YNET: Walla News; 2020.

34. Gesser-Edelsburg A, Shir-Raz Y. Risk communication and infectious diseases in an age of digital media. Routledge studies in public health. London and New York: Routledge; 2016

35. Engdahl E, Lidskog R. Risk, communication and trust: towards an emotional understanding of trust. Public Underst Sci. 2014;23(6):703-17. https://doi. org/10.1177/0963662512460953.

36. Gesser-Edelsburg A, Shir-Raz Y, Walter N, Mordini E, Dimitriou D, James JJ, et al. The public sphere in emerging infectious disease communication: recipient or active and vocal partner? Disaster Med Public Health Prep. 2015:9(4):447-58. https://doi.org/10.1017/dmp.2015.31

37. Gesser-Edelsburg A, Walter N, Green MS. Health care workers--part of the system or part of the public? Ambivalent risk perception in health care workers. Am J Infect Control. 2014;42(8):829-33. https://doi.org/10.1016/j.ajic. 2014.04.012.

\section{Publisher's Note}

Springer Nature remains neutral with regard to jurisdictional claims in published maps and institutional affiliations. 